удК 378.016:81

Т. В. Лискина

Рязанский Государственный университет им. С. Есенина, 2. Рязань, Российская Федерация

Н. С. Паульзен Байкальский государственный университет, г. Иркутск, Российская Федерация

\title{
ВОЗМОЖНОСТИ ОРГАНИЗАЦИИ УЧЕБНОГО ПРОЦЕССА ПРИ ОБУЧЕНИИ ИНОСТРАННЫМ ЯЗЫКАМ В КОНТЕКСТЕ ИНФОРМАЛЬНОГО ВИДА ОБРАЗОВАНИЯ (УРОВЕНЬ ЯЗЫКОВОГО ВУЗА)
}

\begin{abstract}
АНнотАция. В статье уточняется понятие информального образования, рассматривается проблематика реализации возможностей обучения иностранным языкам в рамках информального вида образования на уровне языкового вуза. Обосновывается актуальность и практическая новизна данного вопроса, выявляются различия трех основных видов образования (формального, неформального и информального) и непосредственная роль информального образования как важного компонента полноценного образования личности. Выстраивается первичная классификация основных приемов и стратегий овладения иностранным языком в контексте информального образования (в процессе самообучения), а также авторами предлагаются для рассмотрения возможные источники получения информального образования в повседневной жизни. В качестве технологий, которые может использовать преподаватель для активизации самостоятельной работы студентов над языком и стимулирования желания студентов заниматься информальным образованием, в статье рассмотрены метод проектов и языковой портфель.

кЛючевыЕ словА. Формальное; неформальное; информальное образование; самообучение; методика; иностранные языки; непрерывное образование; языковой портфель; метод проектов.

ИНФОРМАЦИЯ О СТАТЬЕ. Дата поступления 2 октября 2017 г.; дата принятия к печати 19 декабря 2017 г.; дата онлайн-размещения 29 декабря 2017 г.
\end{abstract}

T. V. Liskina S. Yesenin Ryazan State University, Ryazan, Russian Federation

N. S. Paulsen Baikal State University, Irkutsk, Russian Federation

\section{POSSIBILITIES FOR ORGANIZATION OF EDUCATIONAL PROCESS IN TEACHING FOREIGN LANGUAGES IN THE CONTEXT OF INFORMAL EDUCATION (LINGUISTIC UNIVERSITY LEVEL)}

\begin{abstract}
The article specifies the concept of informal education, examines the problems of implementing the opportunities of teaching foreign languages in terms of the informal type of education on the level of a linguistic university. The article substantiates the relevance and practical novelty of this issue, reveals the differences between the three main types of education (formal, non-formal and informal) and the direct role of informal education as an important component of the proper education of an individual. The authors provide the primary classification of basic techniques and strategies for mastering a foreign language in the context of the informal education (in the process of self-learning), as well as offer for the possible sources to be considered for obtaining the informal education in everyday life. The
\end{abstract}

\section{Baikal Research Journal}

электронный научный журнал Байкальского государственного университета 
article considers a project method and language portfolio as the technologies that a teacher can use to activate students' independent work on a language and stimulate the students' desire to practice the informal education.

KEYWORDS. Formal, non-formal, informal education; self-study; methodology; foreign languages; continuous education; language portfolio; project method.

ARTICLE INFO. Received October 2, 2017; accepted December 19, 2017; available online December 29, 2017.

Вопросам организации учебного процесса в условиях информального образования посвящено большое количество общетеоретических / дидактических исследований, что свидетельствует о созданной методологической базе названной образовательной проекции (см. работы Тамбовкиной Т. Ю., Окерешко А. В., Ереминой Е. И., Нелидкина А. М., Бурдиной А. В.). Однако, как показывает анализ, практически отсутствует экспликация данных общедидактических исследований на уровень методики обучения иностранным языкам. Вместе с тем, всё более очевидной становится потребность в привлечении информального образовательного контекста при обучении иностранным языкам, на чем, к сожалению, не акцентируется должное внимание. Необходимость применения данного вида образования при овладении иностранными языками обусловлена спецификой самого учебного предмета: ведь чтобы успешно и результативно овладеть языком, необходимо систематически «включать» его в повседневную коммуникативную, познавательную и трудовую деятельность. Поэтому, основной нашей задачей является анализ роли информального образования, а также конкретизация стратегий самообучения иностранному языку в процессе повседневной жизнедеятельности.

В настоящее время становится совершенно очевидным тот факт, что образование вышло за пределы и рамки формального контекста - его пространственная характеристика теперь зависит не только от аудиторных стен, а от любого жизненного пространства, будь то кинотеатр, клуб по интересам или собственная квартира, вопрос заключается лишь в наличии образовательной (проблемной) ситуации. В таком свете исследователи сегодня разграничивают три вида образования: формальное, неформальное и информальное ${ }^{1}[1]$.

К форлальнолу образованию относится выстроенная в иерархическом и хронологическом порядке система подготовки от дошкольного до профессионального образования (включая аспирантуру и докторантуру), а также некоторые виды дополнительного образования, предполагающие выдачу документа (свидетельства) государственного образца. Главным критерием является тот факт, что такое обучение заканчивается выдачей общепризнанного аттестата или диплома. К нефорлальнолу образованию можно отнести все формы организации учебного процесса за пределами классической формальной системы подготовки. Обучение, как правило, не сопровождается выдачей документов государственного образца. В данном случае мы можем говорить об обучении в общественных организациях, клубах, кружках, во время индивидуальных занятий с репетитором².

Определение информального образования является наиболее сложным, так как к нему можно отнести всю деятельность человека, которую он осуществляет на протяжении всей жизни - приобретение различных ценностных ориентаций, установок, навыков и знаний из повседневного опыта, общения, а также влияние социального окружения (начиная от семейного общения, общения с коллегами на работе и однокурсниками в университете, заканчивая современными средствами

\footnotetext{
1 Образование: лекция 8 / ИНТУИТ. URL: http://www.intuit.ru/studies/courses/ 3465/707/ lecture/16764 (дата обращения: 07.04.2017).

2 Меморандум непрерывного образования Европейского Союза. URL: http://www.znanie.org/ docs/memorandum.html (дата обращения: 07.04.2017).
}

\section{Baikal Research Journal}


информации и коммуникации). Как отмечает А. В. Окерешко, «границы этого понятия достаточно размыты, и информальное образование может происходить как в рамках формального (к примеру, постоянное общение), и в рамках неформального» [2]. В данной работе мы будем придерживаться той точки зрения, что инфорлальное образование - это индивидуальная познавательная деятельность человека, осуществляемая ежедневно и при этом не носящая обязательный целенаправленный характер. Оно также не структурировано и не ведет к официальной сертификации. Информальное образование во многом совпадает со структурой жизнедеятельности человека ${ }^{3}$.

Информальное образование активно, хотя зачастую и не на осознаваемом уровне, влияет на человека, на его жизненные установки, на систему жизненных ценностей. «Во время разговора с друзьями, близкими или просто с попутчиками мы узнаем новые вещи. Пытаясь сделать что-то впервые, мы также учимся. Учебой можно считать просмотр телевизионных передач, посещение музея, чтение книг, прогулки по Интернету, просто размышления на тему», - пишет известный теоретик образования Дж. Филд [3, с. 8].

Важной целью обучения и самообучения иностранному языку в языковом вузе является развитие компетениии самообучения иностранному языку, представляющей собой готовность, способность и умения личности управлять собственным процессом овладения языками, что означает активное и детальное владение всеми шагами учебной деятельности, включая ее планирование, осуществление и контроль [4, с. 19].

В процессе (само)обучения студент языкового вуза применяет различные приемы учебной деятельности и использует множество средств для достижения своих академических и личностных целей. Так, говоря о приемах и универсальных действиях, которыми пользуется студент языкового вуза для успешного самостоятельного овладения языком, мы, опираясь на положения ФГОС (переносимые на уровень вуза на практические занятия, где они также способствуют развитию коммуникативной компетенции), которые, в свою очередь, основываются на взглядах И. Л. Бим («общеучебные умения»), И. А. Зимней («ключевые компетенции»), К. С. Махмурян («филологические компетенции»), А. В. Хуторского и др., выделяем следующие группы:

1. Регулятивные действия:

- самоконтроля / рефлексии;

- (само)организации учебного общения и самостоятельной работы;

- планирования работы с учебным материалом и другими видами информации.

2. Познавательные действия:

- поиска, обработки, анализа, присвоения, передачи информации на иностранном языке (в т.ч. на основе текстов разных типов и форматов, разных информационных источников);

- действия со знаково-символическими средствами,

- универсальные действия (анализ, синтез, обобщение, классифицирование и пр.);

- конспектирования (note-taking);

- оформления заметок, примечаний (note-making).

3. Специальные приемы, конкретизированные для решения узких задач:

- слушания с разной степенью понимания;

- пересказа;

- различных видов чтения;

- и др.

${ }^{3}$ Меморандум непрерывного образования Европейского Союза. URL: http://www. znanie .org/ docs/memorandum.html (дата обращения: 07.04.2017).

\section{Baikal Research Journal}


В процессе овладения иностранным языком (ИЯ) необходима их системная и систематическая реализация, так как изучающему необходимо развивать свою память, искать более удобные для него стратегии фиксации и запоминания информации, уметь подбирать синонимы и использовать перифраз, развивать лингвистическую догадку, планировать и организовывать процесс своей учебной деятельности, проводить рефлексию и самоконтроль, уметь взаимодействовать с собеседником.

Применяя данные стратегии в контексте информального образования, изучающий иностранный язык может обращаться к различным источникам и средствам, которые помогут ему в овладении языком и эффективной организации его самостоятельной работы. Полагаем, к наиболее распространенным источникам получения знаний в информальной внеурочной деятельности можно отнести: 1) фильмы и сериалы, 2) компьютерные игры и виртуальные сети, 3) новостные сайты и другие интернет форумы и блоги, 4) тексты иностранных песен, 5) рекламные ролики и объявления, 6) различные приложения на иностранном языке (сайты продаж, заказов, группы по интересам), 7) участие в экскурсиях в стране изучаемого языка, помощь иностранным туристам, помощь в переводе. Предложенный список будет уточняться и корректироваться в ходе дальнейшего (в т.ч. эмпирического) исследования.

Используя выделенные ранее группы приёмов в перечисленных выше видах повседневной информальной деятельности, обучающийся может не только закреплять уже освоенное, но также и продолжать совершенствовать уровень владения языком, доводя до автоматизма использование грамматических правил, лексических единиц, развивая свою лингвистическую догадку, память, кругозор.

Систематизируем далее виды учебной информальной деятельности, соотнеся их с рассмотренными группами приёмов (см. табл.).

\section{Источники информального образования и приемы его получения}

\begin{tabular}{|c|c|c|c|}
\hline $\begin{array}{c}\text { Источни- } \\
\text { ки }\end{array}$ & $\begin{array}{l}\text { Просмотр фильмов, сериа- } \\
\text { лов, прослушивание песен, } \\
\text { чтение книг и журналов }\end{array}$ & $\begin{array}{c}\text { Компьютерные игры } \\
\text { и приложения, вирту- } \\
\text { альные сети и интернет } \\
\text { ресурсы }\end{array}$ & $\begin{array}{c}\text { Рекламные ролики и объ- } \\
\text { явления, сайты продаж } \\
\text { и заказов, общение } \\
\text { с иностранцами }\end{array}$ \\
\hline $\begin{array}{l}\text { Приемы } \\
\text { и страте- } \\
\text { гии }\end{array}$ & $\begin{array}{l}\text { - } 1 \\
\text { Общеучебные (регулятив- } \\
\text { ные и познавательные) } \\
\text { действия: } \\
\text { - самоконтроля; } \\
\text { - планирования самостоя- } \\
\text { тельной работы; } \\
\text { - поиска, обработки, ана- } \\
\text { лиза информации на ИЯ; } \\
\text { - действия со знаково-сим- } \\
\text { волическими средствами и } \\
\text { универсальные действия; } \\
\text { - оформления заметок, } \\
\text { примечаний } \\
\quad 2 \\
\text { Специальные действия: - } \\
\text { слушания с разной степе- } \\
\text { нью понимания; } \\
\text { - различных видов чтения; } \\
\text { - самостоятельный подбор } \\
\text { материалов; }\end{array}$ & \begin{tabular}{l}
\multicolumn{1}{c}{1} \\
Общеучебные (регуля- \\
тивные и познаватель- \\
ные) действия: \\
- самоконтроля и реф- \\
лексии; \\
- планирования само- \\
стоятельной работы с \\
различными видами \\
информации; \\
- поиска, обработки, ана- \\
лиза информации на ИЯ; \\
- универсальные дей- \\
ствия (анализ, класси- \\
фицирование); \\
- оформления заметок \\
Специальные действия: \\
Спенй \\
- слушания с разной \\
степенью понимания; \\
- различных видов \\
чтения;
\end{tabular} & $\begin{array}{l}1 \\
\text { Общеучебные (регулятив- } \\
\text { ные и познавательные) } \\
\text { действия: } \\
\text { - поиска, обработки, ана- } \\
\text { лиза информации на ИЯ; } \\
\text { - действия со знако- } \\
\text { во-символическими сред- } \\
\text { ствами; } \\
\text { - универсальные действия } \\
\text { (анализ, синтез, обобще- } \\
\text { ние, классифицирование); } \\
\text { - рефлексии и самокон- } \\
\text { троля; } \\
\text { - оформления заметок } \\
\quad 2 \\
\text { Специальные действия: } \\
\text { - слушания с разной сте- } \\
\text { пенью понимания; } \\
\text { - пересказа; } \\
\text { - различных видов чтения; }\end{array}$ \\
\hline
\end{tabular}

\section{Baikal Research Journal}


Окончание табл.

\begin{tabular}{|c|c|c|c|}
\hline $\begin{array}{c}\text { Источни- } \\
\text { ки }\end{array}$ & $\begin{array}{l}\text { Просмотр фильмов, сериа- } \\
\text { лов, прослушивание песен, } \\
\text { чтение книг и журналов }\end{array}$ & $\begin{array}{c}\text { Компьютерные игры } \\
\text { и приложения, вирту- } \\
\text { альные сети и интернет } \\
\text { ресурсы }\end{array}$ & \begin{tabular}{|c|} 
Рекламные ролики и объ- \\
явления, сайты продаж \\
и заказов, общение \\
с иностранцами \\
\end{tabular} \\
\hline & $\begin{array}{l}\text { - конспектирование инте- } \\
\text { ресных заметок, моментов, } \\
\text { фраз из фильмов, песен, } \\
\text { диалогов; } \\
\text { - запоминание устойчи- } \\
\text { вых фраз, сокращений, } \\
\text { крылатых выражений; } \\
\text { - применение догадки, } \\
\text { изучение новых слов } \\
\end{array}$ & $\begin{array}{l}\text { - запоминание устойчи- } \\
\text { вых фраз и выражений, } \\
\text { сокращений; } \\
\text { - применение догадки и } \\
\text { изучение новых слов; } \\
\text { - практика изученного } \\
\text { материала в общении в } \\
\text { чатах/беседах }\end{array}$ & $\begin{array}{l}\text { - применение догадки и } \\
\text { изучение новых слов; } \\
\text { - практика языка при за- } \\
\text { казах/покупках/общении; } \\
\text { - анализ иностранных сло- } \\
\text { ганов, брендов, названий; } \\
\text { - запоминание ключевых } \\
\text { фраз, сокращений, устой- } \\
\text { чивых выражений, идиом }\end{array}$ \\
\hline
\end{tabular}

Источник: составлено авторами по [5, 6, 7].

Что может использовать в своей работе преподаватель, чтобы обратить внимание и интерес студентов на применение данных методов и приемов и на использование с умом источников информального образования? Как он может научить рационально и эффективно выстраивать самостоятельную работу над языком? Одними из основных педагогических технологий, которые преподаватели и студенты могут применять на занятиях для данных целей, в настоящее время выступают проектная деятельность и языковой портфель, благодаря их личностной ориентации и большой степени самостоятельной творческой работы в процессе оформления.

Проектная методика предполагает индивидуальную работу над темой, которая вызывает наибольший интерес у каждого участника проекта, самостоятельный подбор источников информации, планирование и выполнение поставленных задач, что, несомненно, влечет за собой повышенную мотивированную активность учащегося. Сравнивая метод проектов с традиционными подходами, очевидным становится ряд его преимуществ, состоящих в том, что процесс обучения максимально приближается к практике; меняется позиция учащегося в образовании; учебная деятельность приобретает творческий поисковый характер [8]; изучающий прибегает к различным источникам и средствам получения информации, тем самым пользуясь методами информального образования.

Проектная работа предусматривает включение обще-учебных механизмов запоминания и воспроизведения информации; передачи информации другим; применения знаний в вариативных ситуациях; а также оказывает содействие раскрытию возможностей студента, его инициативы и самостоятельности, определению личностно значащих и социально ценностных перспектив [9]. В процессе работы над проектом студент языкового вуза, в зависимости от выбранной темы и направленности, может обращаться к различным информальным источникам и ресурсам, участвовать в иноязычном общении, анализе иностранных материалов, тем самым осуществляя самостоятельный подбор информации, конспектируя необходимые в дальнейшей работе иноязычные данные и материалы, занимаясь переводом и анализом незнакомых структур, запоминая новую и закрепляя уже изученную информацию и грамматические правила, развивая лингвистическую догадку, этимологический интерес, остроту мышления и беглость в использовании иностранного языка.

Языковой портфель определяется как пакет рабочих материалов, которые представляют тот или иной опыт/результат учебной деятельности обучаемого по овладению иностранным языком. Такой пакет материалов дает возможность самостоятельно анализировать и оценивать объем учебной работы, спектр достижений в области изучения языка и иноязычной культуры, динамику овладения

\section{Baikal Research Journal}

электронный научный журнал Байкальского государственного университета 
изучаемым предметом в различных аспектах, а также опыт учебной деятельности в данной области [10]. Особое педагогическое значение языкового портфеля как учебного средства состоит в том, что он направлен на актуализацию самостоятельной учебной деятельности по овладению иностранным языком. В данном случае создаются оптимальные условия для формирования учебной компетенции обучаемого в области изучения языка и развития его продуктивной учебной деятельности, формируются соответствующие учебные стратегии и умения, необходимые для эффективной самостоятельной работы. В определенной степени это можно соотнести с составлением своего индивидуального учебного средства, которое, в отличие от видов работы, стимулирующих иноязычное речевое общение, создает ситуацию развития и обеспечивает реальную вовлеченность и личную ответственность за ход учебного процесса.

Российский языковой портфель включает общеевропейские компетенции владения иностранным языком, которые внесены в Европейский языковой портфолио. Его задачей является обучение студентов умению изучать язык по принципу автономии в течение всей жизни, объективно оценивать свой уровень владения языковыми навыками и презентовать себя любому лицу или организации [11]. В современной практике преподавания иностранных языков студентами и преподавателями могут быть эффективно использованы различные виды языкового портфеля в зависимости от его целевой направленности. Для достижения целей информального образования наиболее подходящими нам представляются языковой портфель как инструмент автономного изучения иностранного языка (Language Learning Portfolio), так как данный вид языкового портфеля может варьироваться в зависимости от одноцелевой или комплексной направленности, например, языковой портфель по чтению (Reading Portfolio), по говорению (Speaking Portfolio), по письму (Writing Portfolio), что будет отражать развитие навыков студента благодаря самостоятельной практике определенных аспектов языка; а также многоцелевой языковой портфель, включающий различные цели в области овладения иностранным языком (Comprehensive Language Portfolio) [12]. Просмотр иноязычных фильмов и конспектирование необходимых или заинтересовавших фраз, прослушивание аудиоматериалов и запоминание новых слов и выражений, применение догадки и этимологического анализа при изучении новой лексики, использование устойчивых фраз и грамматических конструкций при общении с иностранными туристами - все вышеперечисленные приемы, используемые в информальном изучении иностранного языка, отражают процессы работы с различными аспектами языка и могут быть занесены в частные блоки языкового портфеля.

Таким образом, языковой портфель как педагогическая технология является не только надежным инструментом для определения студентами своих достижений в овладении иностранным языком, но также и вдохновляет на дальнейшее совершенствование своих знаний и умений, развивает заинтересованность в изучении языков на протяжении всей жизни, тем самым не ограничивая его лишь рамками учебной программы, но отражая реальный результат и подкрепляя желание и интерес продолжать изучение языка в процессе повседневной жизнедеятельности.

Подводя предварительные итоги, обобщим основные результаты, изложенные в данной статье:

1. Проанализировано и уточнено понятие «информального образования», выявлены его особенности в сравнении с формальным и неформальным видами; согласно взглядам отечественных и зарубежных ученых, занимающихся данным вопросом, информальное образование обладает следующими характеристиками: оно имеет не целенаправленный характер, не имеет ни определенной структуры,

\section{Baikal Research Journal}

электронный научный журнал Байкальского государственного университета 
ни официальной сертификации, происходит в процессе повседневной жизнедеятельности человека на протяжении всей жизни.

2. На основе обозначенных в ФГОС универсальных учебных действий и компетенций, систематизированы приемы и стратегии, используемые в контексте информального образования: как обще-учебные действия (самоконтроля, планирования работы, рефлексии, запоминания, конспектирования и оформления заметок), так и специальные (слушания, различных видов чтения, запоминания устойчивых фраз, сокращений, идиом, применения догадки и этимологического анализа, практики языка при заказах/общении в интернете/с туристами и т.д.), с целью приложения их к информальному образованию на уровне университета.

3. Авторами статьи систематизированы и предложены для рассмотрения источники, применяемые студентами в информальном образовании (фильмы и сериалы, компьютерные игры и интернет ресурсы, виртуальные сети и блоги, журналы и книги, песни, рекламные ролики и объявления, участие в экскурсиях в стране изучаемого языка, общение с иностранными туристами, помощь в переводе), и приемы, используемые в ходе работы с ними.

4. Авторами выделены и рассмотрены такие образовательные технологии, как языковой портфель и метод проектов, которые позволяют студентам применять выделенные ранее учебные действия и приемы в процессе (самостоятельной) работы; отражена роль данных образовательных технологий в актуализации информального (само)образования.

5. Выявлена роль информального образования при (само)обучении иностранным языкам в процессе повседневной жизнедеятельности, заключающаяся в том, что систематическое включение иностранного языка в повседневную коммуникативную, трудовую, познавательную деятельность, использование дополнительных источников и средств для изучения и совершенствования языка, умение выбирать, классифицировать нужную и полезную информацию, источники и выстраивать свои самостоятельные траектории/ цели работы над языком позволяют студентам достигать более высоких результатов в освоении языка.

Данная область образования является широким объектом для исследования. Продолжая работу над обозначенной темой, предоставляется возможным глубже изучить взаимодействие всех трех видов образования и непосредственно практическую пользу информального вида образования в работе студентов с языком, а также способы реализации самообучения иностранным языкам в контексте информального образования и возможности преподавателя вуза в актуализации данного вида образования. Представленные в статье классификации и примеры получат практическую апробацию и послужат материалом для дальнейших статей по данной проблеме.

\section{Список использованной литературы}

1. Колесников А. А. Профорентационный компонент как интегративная составляющая обучения иностранному языку в профильной школе / А. А. Колесников // Иностранные языки в школе. - 2015. - № 4. - С. 2-9.

2. Окерешко А. В. Информальное образование: опыт определения понятия / А. В. Окерешко // Непрерывное образование взрослых : материалы междунар. форума. - СПб. : ИНОВ, 2015. - С. 67-72.

3. Field J. Lifelong Learning and the New Education Order / J. Field. - Trenthaw Books, 2000. $-181 \mathrm{p}$.

4. Тамбовкина Т. Ю. Самообучение иностранным языкам как подсистема вузовского лингвистического образования : автореф. дис. ... д-ра педагог. наук : 07.06.2007 / Т. Ю. Тамбовкина. - М., 2007. - 50 с.

\section{Baikal Research Journal}


5. Махмурян К. С. Содержание понятий «филология» и «филологическая компетенция» на современном этапе / К. С. Махмурян // Вестник Московского университета. Сер. 19, Лингвистика и межкультурная коммуникация. - 2008. - Вып. 3. - С. 202-207.

6. Хуторской А. В. Ключевые компетенции и образовательные стандарты [Электронный ресурс] / А. В. Хуторской // Интернет-журнал «Эйдос». - 2002. - 23 апр. - Режим доступа: http://eidos.ru/journal/2002/0423.htm (дата обращения: 05.04.2017).

7. Зимняя И. А. Ключевые компетенции - новая парадигма результата современного образования [Электронный ресурс] / И. А. Зимняя // Интернет-журнал «Эйдос». 2006. - 5 мая. - Режим доступа: http://www.eidos.ru/journal/2006/0505.htm (дата обращения: 05.04.2017).

8. Позднеева С. И. Проектная деятельность в практике учителя начальной школы / С. И. Позднеева, Т. В. Кузнецова // Вестник ТПГУ. Сер. Педагогика. - 2006. Вып. 10 (61). - С. 65-66.

9. Ручинская Т. Педагогическая технология: метод проектов [Электронный ресурс] / Т. Ручинская // Студенческий научный форум : 3-я общерос. студ. электрон. науч. конф., 15-20 февр. 2011 г. - Режим доступа: https://www.rae.ru/forum2011/87/1331 (дата обращения: 02.06. 2017).

10. Прелова Е. В. Реализация личностно-деятельностного подхода в рамках технологии «языковой портфель» / Е. В. Прелова // Сибирский педагогический журнал. — 2012. № 5. - С. 61-64.

11. Иванченко Т. Ю. Языковой портфолио как стратегия изучения иностранного языка в течение всей жизни / Т. Ю. Иванченко // Молодой ученый. — 2013. — № 5 (52). C. 704-709.

12. Иванченко Т. Ю. Технология «языковой портфель» как инструмент мотивации к изучению иностранного языка на протяжении всей жизни / Т. Ю. Иванченко // Молодой ученый. - 2013. - № 12. - С. 462-465.

\section{References}

1. Kolesnikov A. A. Career-guidance component as an integrative part of teaching a foreign language in the specialized school. Inostrannye yazyki $v$ shkole $=$ Foreign Languages at School, 2015, no. 4, pp. 2-9. (In Russian).

2. Okereshko A. V. Informal education: experience of definition. Nepreryvnoe obrazovanie vzroslykh. Materialy mezhdunarodnogo foruma [Continuous adult education. Materials of the International Forum]. Saint Petersburg, INOV, 2015, pp. 67-72.

3. Field J. Lifelong Learning and the New Education Order. Trenthaw Books, 2000. 181 p.

4. Tambovkina T. Yu. Samoobuchenie inostrannym yazykam kak podsistema vuzovskogo lingvisticheskogo obrazovaniya Avtoref. Kand. Diss. [Self-study of foreign languages as a subsystem of university linguistic education. Cand. Diss. Thesis]. Moscow, 2007. 50 p.

5. Makhmuryan K S. The content of terms "philology" and "philological competence» in the modern context. Vestnik Moskovskogo universiteta. Seriya 19, Lingvistika i mezhkul'turnaya kommunikatsiya $=$ Bulletin of Moscow University. Series 19. Linguistics and Cross-Cultural Communication, 2008, Iss. 3, pp. 202-207. (In Russian).

6. Khutorskoi A. V. Key competencies and educational standards. Internet-zhurnal "Eidos»= Internet Journal «Eidos», 2002, 23 avr. Available at: http://eidos.ru/journal/2002/0423. htm. (In Russian).

7. Zimnyaya I. A. ey competencies are a new paradigm of modern education result. Internet-zhurnal «Eidos»= Internet Journal «Eidos», 2006, 5 may. Available at: http://www. eidos.ru/journal/2006/0505.htm. (In Russian).

8. Pozdneyeva S. I., Kuznetsova T. V. Project activity in practice of primary school teachers. Vestnik Tverskogo Gosudarstvennogo Universiteta. Seriya: Pedagogika = Herald of Tver State University. Series: Pedagogy and psychology, 2006, iss. 10 (61), pp. 65-66. (In Russian).

9. Ruchinskaya T. Pedagogical technology: method of projects. Studencheskii nauchnyi forum 3-ya obshcherossiiskaya studencheskaya elektronnaya nauchnaya konferen-tsiya, 1520 fevralya 2011 g. [Student Scientific Forum. The $3^{\text {rd }}$ All-Russian Student Electronic Scientific Conference, February 15-20, 2011]. Available at: https://www.rae.ru/forum2011/87/1331. (In Russian).

\section{Baikal Research Journal}


10. Prelova E. V. Implementation of the personality-activity approach in terms of the technology of «language portfolio». Sibirskii pedagogicheskii zhurnal = Siberian Pedagogical Journal, 2012, no 5, pp. 61-64. (In Russian).

11. Ivanchenko T. Yu. Language portfolio as a strategy for studying a foreign language throughout life. Molodoi uchenyi = Young Scientist, 2013, no. 5 (52), pp. 704-709. (In Russian).

12. Ivanchenko T. Yu. Technology of «language portfolio» as a tool for motivation of studying foreign language throughout life. Molodoi uchenyi = Young Scientist, 2013, no 12, pp. 462-465. (In Russian).

\section{Информация об авторах}

Лискина Талара Владилировна - магистрант, кафедра лингвистики и межкультурной коммуникации, Институт иностранных языков, Рязанский государственный университет им. С. Есенина; г. Рязань, ул. Свободы, д. 46, каб. 38, e-mail: listpismo@mail.ru

Паульзен Наталья Сергеевна - кандидат филологических наук, доцент, кафедра иностранных языков, Байкальский государственный университет, 664003, г. Иркутск, ул. Ленина, 11, ауд. 1-413; e-mail: alla_po@mail.ru

\section{Authors}

Tamara V. Liskina - Master Degree Student, Chair of Linguistics and Intercultural Communication, Institute of Foreign Languages, S. Yesenin Ryazan State University, 46 Svobody St., 390000, Ryazan; e-mail: listpismo@mail.ru

Natalia S. Paulsen - PhD in Philology, Associate Professor, Chair of Foreign Languages, Baikal State University, 11 Lenin Str., 664003, Irkutsk; e-mail: alla_po@mail.ru

\section{Для цитирования}

Лискина Т. В. Возможности организации учебного процесса при обучении иностранным языкам в контексте информального вида образования (уровень языкового вуза) / T. В. Лискина, Н. С. Паульзен // Baikal Research Journal. - 2017. — T. 8, № 4. - DOI : 10.17150/2411-6262.2017.8(4).4.

\section{For Citation}

Liskina T. V., Paulsen N. S. Possibilities for organization of educational process in teaching foreign languages in the context of informal education (linguistic university level). Baikal Research Journal, 2017, vol. 8, no. 4. - DOI : 10.17150/2411-6262.2017.8(4).4. (In Russian).

\section{Baikal Research Journal}

